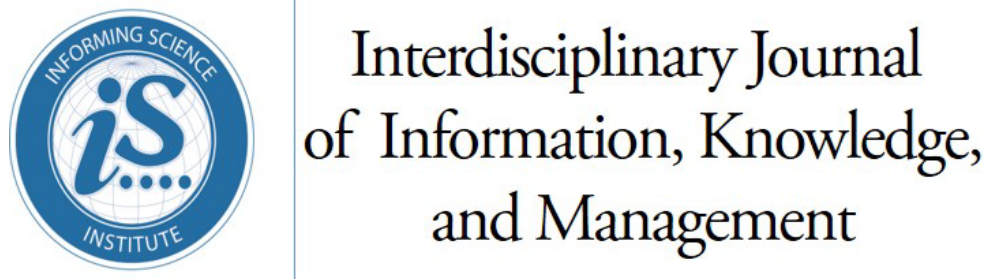

An Official Publication

of the Informing Science Institute

InformingScience.org

IJIKM.org

\title{
Volume 12, 2017 \\ THE UTILISATION OF FACEBOOK FOR KNOWLEDGE SHARING IN SELECTED LOCAL GOVERNMENT COUNCILS IN DELTA STATE, NigERIA
}

\author{
Uzoma Heman Ononye * Oshimili South Local Government, \\ Asaba, Delta, Nigeria \\ Rev. Fr. Anthony Igwe University of Nigeria, Enugu \\ Campus, Enugu, Nigeria \\ Ononye.uz@gmail.com \\ Anthonyigwe121@yahoo.com \\ * Corresponding author
}

\section{ABSTRACT}

Aim/Purpose/

Background

Methodology

Contribution
Facebook has made it possible for organisation to embrace social and network centric knowledge processes by creating opportunities to connect, interact, and collaborate with stakeholders. We have witnessed a significant increase in the popularity and use of this tool in many organisations, especially in the private sector. But the utilisation of Facebook in public organisations is at its infancy, with many also believing that the use of Facebook is not a common practice in many public organisations in Nigeria. In spite of this fact, our discernment on the implications of Facebook usage in public organisations in Nigeria, especially organisations at the local level, seem to be remarkably limited. This paper specifically sought to ascertain if Facebook usage influenced inward and outward knowledge sharing in the selected local government councils in Delta State, Nigeria

The qualitative method was adopted. The study used interview as the primary means of data gathering. The study purposively sampled thirtysix employees as interviewees, twenty from Oshimili South and sixteen from Oshimili North local government councils respectively. The thematic content analysis method was used to analyse interview transcripts.

This research made distinct contributions to the available literature in social knowledge management, specifically bringing to the fore the intricacies surrounding the use of Facebook for knowledge sharing purposes in the public sector.

Accepted by Editor Geoffrey Liu | Received: April 29, 2017 | Revised: August 23, August 25, September 4, 2017 | Accepted: September 5, 2017.

Cite as: Ononye, U. H., \& Igwe, A. (2017). The utilisation of Facebook for knowledge sharing in selected local government councils in Delta State, Nigeria. Interdisciplinary Journal of Information, Knowledge, and Management, 12, 269-282. Retrieved from http://www.informingscience.org/Publications/3854

(CC BY-NC 4.0) This article is licensed it to you under a Creative Commons Attribution-NonCommercial 4.0 International License. When you copy and redistribute this paper in full or in part, you need to provide proper attribution to it to ensure that others can later locate this work (and to ensure that others do not accuse you of plagiarism). You may (and we encourage you to) adapt, remix, transform, and build upon the material for any non-commercial purposes. This license does not permit you to use this material for commercial purposes. 
Findings The local government councils were yet to appreciate and utilise the interactive and collaborative nature of Facebook in improving stakeholders' engagement, feedback, and cooperation. Facebook was used for outward knowledge sharing but not for inward knowledge sharing.

Recommendations Local government councils should encourage interaction via Facebook, show willingness to capture knowledge from identifiable sources, and effectively manage critical knowledge assets in order to build trust, cooperation, and confidence in the system. To gain strategic benefits from the use of Facebook for synchronous communication of knowledge, local government councils should ensure that the use of such technology is aligned with strategic plans and that directional change is in line with the new knowledge economy, where interaction and collaboration through technology are seen as strategic imperatives for continued success and sustainability. In addition, local government councils need to train stakeholders on effective use of Facebook for knowledge sharing, with special emphasis on how, why, who, when, and where to use such tool for knowledge sharing activities.

Keywords social media, Facebook, knowledge sharing

\section{INTRODUCTION}

With the highly volatile nature of today's economic environment and the need for organisations to stay relevant and competitive, there has been a paradigm shift from unidirectional knowledge processes to those that are social and network centric (Obermayer-Kovács \& Wensley, 2012). The emergence of social media tools has made this a possibility by creating opportunity for organisations to clearly adopt the role of knowledge-based organisation and leverage on the competencies of knowledge workers through social interactions. The theoretical potential of social media as situated in the knowledge management context, demonstrates that effective use can help improve the extraction and utilisation of knowledge in organisations, particularly in those areas where the potential for information silos are quite high. Organisational stakeholders are getting connected to each other through social media in more ways than previously imagined. In Nigeria, a social media tool that has grown tremendously over the years in terms of popularity and usage is Facebook. In 2007 the number of Facebook users stood at 400,000. This figure rose to over 4.3 million users in 2011. As of 2016, Facebook recorded 16 million active accounts with 7.2 million daily users -- the highest in Africa, making Nigerians the most active users in the continent (Danbatta, 2017). Available data clearly indicate that Facebook is the most popular and subscribed social networking site in Nigeria. The increased usage can be attributed to the synthesisation of the functions of most of the widely used web-based communication tools designed to support the publication of multimedia content often in a variety of formats (Olajide, \& Oyeniran, 2014), RSS feeds such as news feeds and blogs, group formation, dynamic searches, mass and individual messaging, event hosting, and e-mail as well as for networking. Also, people with little or no technological background or expertise can utilise its breadth of functions with smart devices to connect, interact and collaborate (Sharma, 2008 in ChanOlmsted, Cho, \& Lee, 2013). The primal appeal of Facebook in bringing the speed, scale, and economics of the internet to social interactions has made organisations to utilise its features in creating an informal platform where they can connect and communicate with stakeholders in a dynamic manner (McKinsey Global Institute, 2012).

The utilisation of Facebook in the Nigerian public sector became noticeable during the 2011 election. The Independent National Electoral Commission (INEC), a public organisation saddled with the responsibility of conducting free and fair elections, made extensive use of Facebook and other social media tools to provide a check to the legitimacy of the national elections and get situation reports from the electorates and other stakeholders at polling stations. Though it was preconceived as 
an experiment, its efficacy in sharing electoral information and elicitation of feedback was considered remarkable. It is imperative to also mention that its use to engage voters in such manner was the first in Africa. In January 2012, the Nigerian government was criticised following the increment in the price of premium motor spirit (PMS). Its attendant Occupy Nigeria Protest, driven partly by the social media, crippled the economy and exacerbated the need for the government and its agencies to connect and interact more with the public to understand their needs and expectations in this everchanging time (Olayiwola, 2014). It is believed that these salient events somewhat set the stage for a cross section of public organisations in Nigeria to extend their reach and engagement by adopting platforms for conversations that offers more information and education to the public, and unfiltered feedback or suggestions to the organisation. This can potentially enrich their regulatory role and interventions in various policy areas (Danbatta, 2017). Ting (2011, as cited in Omede, 2015) asserts that the increase in the use of social media for self-expression and the sharing of views, ideas, and opinions have spurred the recognition of social media as a revolutionary corporate tool that changes the manner in which public organisations and stakeholders participate in the knowledge sharing process with the aim of improving business operations and service delivery. We have witnessed some public organisations in Nigeria use Facebook as a facet of e-governance. This is to enable participation by providing a formidable platform for stakeholders to have accurate and sufficient information at their fingertips, so as to enable them make rational and informed decisions and take right course of action that is deemed beneficial to them. As a feedback mechanism, Facebook provides the means for stakeholders to register their grievances, feelings, opinions, or ideas and express their assent and dissent concerning specific issues (Dunu, 2013). This acknowledges the assertion of Okoro and Dirim (2009, as cited in Olayiwola, 2014) that through social media, people are able to actively participate and interact freely in discussions that are relevant to public good and can be achieved at the least possible cost.

In the recent past, Facebook has not only changed the relationships of these organisations with the public by creating new platforms for knowledge sharing, but also improved the ability to contribute in the development process by creating a dynamic space for more diverse political opinions, sociocultural viewpoints and a heightened level of stakeholders' participation. The spaces created have opened up avenues for engaging the public concerning different issues as it affects the running of public organisations in Nigeria (Dunu \& Uzochukwu, 2015). The widespread attention on stakeholders' participation in knowledge sharing is underpinned on the belief that bringing together the full breadth of skills, knowledge, and experience across board increases the effectiveness with which organisations can solve problems, avoid repetition of mistakes, and spread the adoption of best practices (Chow, Ho, \& Vera-Munoz, 2008). However, in many public organisations in Nigeria, knowledge is very often insulated because they maintain some form of bureaucratic structures that are not in tune with the realities of this present time, which makes the knowledge sharing process less streamlined and more complex. It takes a significant amount of time - hours, days and possibly weeks to get offline information, though its use may be required immediately. It is therefore likely that majority of pubic organisations in Nigeria use outdated knowledge as a result of delays and frequent changes in the environment, and such an act could jeopardise the functioning and sustainability of such organisations in meeting up to societal demands and expectations (Bamgboje-Ayodele \& Ellis, 2015). The process of sharing meaningful information has been dominated by the use of conventional mass media such as television, radio, and newspaper, irrespective of the obvious demerits of providing one-sided non-interactive messages or information to a large group of people (Chinedu, Chinonye, \& Obi, 2016). The use of mass media channels is prevalent and still the preferred choice to the new media in Nigeria. From all indication, this has blocked popular participation because there has been scarcity of space and airtime given by conventional media to the public to contribute meaningfully to the governance process (Okoro \& Nwafor, 2013). World Bank (2001, as cited in Olufemi, 2012) believes the broadcast communication channels are generic and barely consider the collective interests or needs of the public because of its low interactivity. It is apparent that many public organisations in Nigeria are yet to fully transit from the traditional way of sharing 
knowledge to network-centric knowledge sharing processes, which allows more connectivity and interaction with the public. The dependence on the mass media in Nigeria is somewhat noticeable and cannot be totally discarded, but modern trends of the new media seem to be eroding the gains of the mass media around the globe. As the new media gradually reshapes the manner in which information is shared and acted upon, experts and scholars wonder whether the mass media still command the same level of relevance that made them indispensable in years past for developing credible platform for knowledge sharing (Chinedu et al., 2016).

The Federal Ministry of Agriculture and Rural Development (FMARD) (2015) is of the opinion that the development of the public sector in Nigeria requires active participation of all stakeholders. The fact that public organisations still have limited access to the internet and have yet fully embraced modern social technologies leads to insufficient information flows. This results in sub-optimal use of information for policy development, programme management, collaboration and partnership, and learning and innovation. The knowledge system of any progressive society performs a pivotal function in its development and ensures an effective and efficient flow of information and knowledge between all stakeholders. In spite of this recognition, knowledge sharing via social media tools, specifically Facebook, is not a common practice in many public organisations in Nigeria. For those that do adopt it, it is a far cry from what is expected in an interactive and collaborative process. This affirmed the assertions that the utilisation of Facebook is still at its infancy in the public sector in many African countries (Mosha, Holmner, \& Penzhorn, 2015) and that on the social technographics ladder many public organisations are inactive and continue to rely on yesterday's technology to correct tomorrow's problems (Serrat, 2010). While social media applications such as Facebook have received widespread acceptance and usage in social settings and private organisations, public organisations have been slow to incorporate such technologies into their organisational activities (Murphy, 2010). But it is evident that these organisations are trying to imitate private sector social media initiatives to actively engage stakeholders in policy processes and gain feedback as well as facilitate collaboration with internal and external partners with the belief that it will aptly address the current challenges marked by emerging global issues, rising citizen expectations and knowledge loss from an aging population (Falco, 2011; Mickoleit, 2014). Dzekashu (2015) writes that public organisations across levels have a responsibility to change with changing times and embrace different methods of knowledge collaboration. Failure could lead to losing their edge in the provision of services that are relevant to public needs and interests. In furtherance, when organisations fail to adapt to environmental changes, the failure could lead to knowledge degradation (Thibodaux \& Rouse, 2005 as cited in Dzekashu, 2015).

The business terrain may be undulating but technological affordances are most assuredly levelling organisations and the silos in them. The social interaction of the past, severely restricted by various boundaries, has now been taken online, opening up a world of new possibilities in knowledge sharing. Hence, rather than rely solely on the broadcast communication channels that cannot meet up with emerging global trends that requires fast learning and collaboration, social media tools, specifically Facebook, can be used to complement existing knowledge management practices in public organisations. Evidence also makes clear that for knowledge sharing to be effective, social media tools should be used concomitantly with other social technologies and existing organisational communication and information infrastructures (Stephen \& Galak, 2009, as cited in Chan-Olmsted et al., 2013). In spite of this fact, our discernment on the implications of Facebook usage in public organisations in Nigeria, especially organisations at the local level, seems to be remarkably limited. Since many public organisations in Nigeria are yet to integrate social media tools fully into their present knowledge management paradigms as characterised by relatively little social edge for stakeholders to participate in large numbers, they run the risk of staying disconnected from disparate and isolated knowledge that have significant performance implications. With this in mind, it was therefore pertinent to examine the utilisation of Facebook for knowledge sharing in public organisations, with particular reference to local government councils in Delta State, Nigeria. The objective of the study was to ascertain 
if Facebook usage influenced inward and outward knowledge sharing in the selected local government councils in Delta State, Nigeria.

\section{LITERATURE REVIEW}

\section{FACEBOOK AS A KNOWLEDGE SHARING TOOL}

Originally, Facebook was created in 2004 as an online social networking platform for students in Harvard University; it has since evolved into a widely used social media tool in many organisations. As a web-based social platform, Facebook enables organisations to (1) communicate specific or broadcast messages in an identifiable social network with the aim of knowing and learning; (2) build strategic relations with partners with shared competence and commitment to increasing the economic and social value of knowledge; (3) dynamically engage in conversations and seek contributions that addresses identifiable operational lacunas; (4) promote better transparency and accountability by allowing citizens, businesses, and civil society to see, understand, critique, and monitor government's activities, and find ways to influence decision-making and policies; (5) integrate processes that produce knowledge relevant to the real needs and interests of people for better service delivery; (6) improve inclusion and empowerment by enabling marginalised groups participate in the process, and removing imbalances of power created through information asymmetry, and (7) play a hybrid role of a producer and consumer of knowledge through the learning process (Gregson, Brownlee, Playforth \& Bimbe., 2015; Munro, 2014). The scope for value creation hinges on the particulars or composition of the virtual community and how well the organisation organises its space. But if well implemented, Facebook can effectively bring with it the power of participants. Its influence can only grow because, unlike in the past, control is shared with the crowd and feedback is in real time. Participants generate contents and voice their feelings far and wide on various issues that affect them. From the wisdom of the crowd, reactions can be collected from participants through online polls, comments, and likes, valuable relationships can be built through conversations about people's experiences, higher level engagement can be deployed, and messages, services, programs, policies can be related and refined to better match the needs and expectations of stakeholders. For Facebook to be value oriented and result driven, public organisation must stretch their mindset to understanding emerging mental models and be equipped with strategies that will enable them effectively take part in collaborative relationships, where ideas, opinions, experience, and best practices are shared about how to approach various business and societal problems (Serrat, 2010). As the wave of Facebook continues to sweep across the public sector, it is imperative for each organisation to understand and develop a strategy that is incorporated into existing knowledge processes, particularly in areas where there are stakeholders' touchpoints, so as to better understand the changes in needs and behaviour (Falco, 2011; Mickoleit, 2014).

\section{THE CONCEPT OF KNOWLEDGE SHARING}

Many organisations have recognised the performance implications of knowledge and knowledge management in the promotion of smart growth in a highly dynamic environment. Such smart growth requires, among other things, promoting innovation and knowledge transfer, making full use of information and communication technologies, and ensuring that innovative ideas can be turned into new public services (European Commission, 2010, as cited in Gaál, Szabó, Obermayer-Kovács, \& Csepregi, 2015). Therefore, understanding how knowledge flows across boundaries within an organisation can yield critical insight into where efforts should be targeted to promote collaboration that has significant strategic payoff(s) for the organisation (Cross, Parker, Prusak, \& Borgatti, 2001).

Knowledge sharing has been identified as the most critical area of knowledge management, not only to promote fluidity in the exchange of ideas, experience, and problems, but also to provide linkages between knowledge workers, where knowledge resides, and organisations where knowledge attains its competitive edge and value (Mosha et al., 2015). Wang and Noe (2010, as cited in Gibbs, Rozaidi, \& Eisenberg, 2013) define knowledge sharing as a complex process of making task related and social 
information readily available to others so they may generate new ideas, collaborate to resolve problems, or implement new organisational processes. In public organisations, this translates to individuals and organisations alike mutually exchanging their knowledge components, across social and geographic boundaries. The exchange of knowledge could be tacit (embedded in the mind), explicit (worded and documented knowledge), or both, which allows them collectively to create new knowledge to solve complex problems, develop ideas to implement new processes, and reduce duplication of efforts. Hence, the value of knowledge increases when it is shared with others. Baporikar (2014) simply writes that public organisations are beginning to recognise that the information needed to plan, make decisions, and act is often held inside and outside their own organisation and is collected for widely different purposes and maintained in disparate formats. These organisations are increasingly turning to knowledge sharing strategy for maximising the value of information in providing services and responding to problems. Towley (2000, as cited in Awodoyin, Osisanwo, Adetoro, \& Adeyemo, 2016) posits that the social interaction that emanates from knowledge shared should involve capturing an organisation's objective-related knowledge in addition to the knowledge of its stakeholders, services, and processes, and then sharing that knowledge with the appropriate people throughout the organisation. For the purpose of clarity, the concepts of information sharing and knowledge sharing as used in this study cannot be equated together. Information sharing was seen as the dissemination of mere messages or organised data between public organisations and stakeholders (citizens and businesses). It can be considered as knowledge sharing only when the information is actionable or when the available information has been organised and processed to elicit deeper insight, understanding, experience, or expertise applicable to the current organisational or societal problems.

\section{KNOWLEDGE SHARING CHANNELS IN A SOCIAL DIGITAL NETWORK}

An effective knowledge base should include social collaboration functionality that streamlines the communication process by allowing participants to capture and share knowledge through different communication channels. These knowledge flows are seen as channels through which individuals, knowledge systems, and organisations frequently interact and share information. They constitute complex networks that are still only potential means of knowledge or information exchange, which become value-added only when people use them as tools in their processes of action or to facilitate interaction for efficient use of knowledge (Laihonen \& Lonnqvist, 2011).

Two communication modes are possible in the use of Facebook, which enables public organisations to recognise the influence of external constituents on organisational knowledge base (Murphy, 2010; Wen, 2011). They are "outward" knowledge sharing and "inward" knowledge sharing. Outward knowledge sharing refers to the dissemination of actionable information to the external structure of an organisation. This structure represents the external constituents that have a defined relationship or communication with the organisation, which includes, but is not limited to, corporate bodies, civil societies, and citizens. Facebook allows public organisations to create and publish user generated contents through links, video and pic stories upload, status updates, opinion polls, and campaigns that are topical and of interest to their priority areas. In a bid to be seen as transparent, this function is the most obvious to consider when thinking of using Facebook. Public organisations can develop an ambient awareness of the behaviour of stakeholder when there is a seamless flow of defined data to the task environment. In contrast, inward knowledge sharing is also referred to as knowledge contribution. According to Wen (2011) inward knowledge sharing is viewed as occurring through the exchange of messages or information that add significant value to the online social network and create a public good of collective knowledge. The use of Facebook has the capacity to allow interaction by empowering stakeholders, irrespective of their social affiliation and geographic dispersion, to participate and strongly contribute in advancing good governance. This mode of sharing goes a long way in improving stakeholders' trust and contribution in the system, since it is intended to locate and access the expertise, insights, experiences, and informed opinions of stakeholders, as well as increasing the potential for serendipitous discovery of knowledge from formerly unconnected sources. 
The communication channels enable public organisations to comprehensively map their knowledge processes and develop an infrastructure for effective online social networking. Holistically, the understanding and rationalisation of interaction processes and knowledge flows or channels has a crucial role in the quest for methods and tools for developing service productivity (Laihonen, \& Lonnqvist, 2011). For public organisations to harness the possibilities of Facebook effectively, it should be seen as a forum for constructive discussion and a vehicle for collective action. With this, the interaction between public organisations and stakeholders will deepen, the strategic direction will be known and well assimilated, and stakeholders will be afforded the opportunity to participate and contribute immensely to the processes of policy formulation, implementation, and monitoring.

\section{THEORETICAL FRAMEWORK: THE DYNAMICS CAPABILITY APPROACH}

The dynamic capabilities approach was proposed by Teece and Pisano (1994). This approach argues that success is factored on capabilities that enable organisations to anticipate, shape, and adapt to rapidly changing environments. Hence, corporate survival requires organisations to recognise the shifting character of the environment as marked by changes in technology and the key role of knowledge in aptly adapting, integrating, and reconfiguring internal and external competencies and processes towards changing environment (Teece \& Pisano, 1994). Therefore, this study anchors on the fact that in this technology and knowledge-driven era, for public organisations to achieve sustainable edge in the delivery of services, policies, programmes, etc. that are in line with evolving societal interests and expectations, they should develop or reconfigure their processes by creating platforms that allow for more interaction and collaboration through the incorporation of new technologies. However, we believe that with Facebook being used for knowledge sharing as a result of its wider reach and audience, such capabilities may be strengthened. Public organisations may not only be exposed to recent ideas and best practices, but also have better understanding of the collective needs and expectations of the public, especially those groups that have been marginalised, because knowledge sharing will presumably become more open, interactive and outwardly focused.

\section{PREVIOUS STUDIES}

Vacquez and Velez (2011) indicated that social media is seen in the corporate world as a strategic communication partner, driving new and unique possibilities for organisations to converse with citizens and listen to their contributions. In this knowledge driven era, citizens are becoming active users rather than passive individuals, dramatically changing the functioning of the society. The use of social media for knowledge management connects organisations to stakeholders affected by their decisions and operations. With the fundamental shift in connective capacity, those users of social media external to an organisation can create knowledge about their activities by sharing information or comments about any given operational concern (Flanagin \& Bator, 2011). Kuhus (2011, as cited in Okoro \& Nwafor, 2013) observed that the communication experience has changed to make interactions and conversations with stakeholders more visible and actionable. Social media has provided avenues for stakeholders to explicitly communicate grievances, suggestions, opinions, or concerns on a range of operational issues that affect them. With such social technologies, established authority no longer operates in isolation and cannot undermine the people's contributions in the governance process. In another study, Mosha et al. (2015) argued that the utilisation of social media tools should not be solely for broadcasting information, but also for listening to the suggestion and opinions of stakeholders, so that government agencies can discover problems and improve their service. With the adoption of social media, public organisations have been provided with real-time opportunities for participation and feedback. They give public organisations new tools to pilot, experiment, evaluate, and re-design services as informed by stakeholders' needs ahead of their full roll-out (Mickoleit, 2014). Dunu and Uzochukwu (2015) reported that social media has created an interactive platform for public organisations in conjunction with stakeholders to contribute significantly to the development process of the society, by creating a space for more diverse opinions and a burgeoning level of participation. This affords a big opportunity for engaging stakeholders on different issues and concerns that affect the 
operations of these establishments in Nigeria. However, McCorkindale (2010, as cited in AndohQuainoo \& Annor-Antwi, 2015) aptly pointed out that communication on the Facebook page in many public organisations was one-sided, resembled a monologue, and thus neglected the interactive potential of Facebook that supports constructive feedback from stakeholders. Despite the countless potential that social media brings to synchronous communication, many organisations seem focused on social media primarily for broadcasting information. Aizhan, Massimo, and Claudia's (2017) review found that public organisations in a bid to keep stakeholders informed on their activities post operational or service-related information for public consumption on Facebook. But these studies have not reported if comments and suggestions posted on social media had directly influenced operational or service-related policies. However, several authors implicitly pointed out that social media use does influence decisions or actions taken by public organisations, because negative comments and suggestions towards policies echoed those found in public opinion polls.

Of those mentioned above, several extant studies have tried to capture the growing relevance of social media in its entirety in today's organisation. We have witnessed a significant build-up of literature in this regard, but studies on knowledge sharing practices in the public sector are still at their infancy. The growing interest of public organisations in adopting social technologies shows that the opportunities offered and contributions to knowledge sharing are too steep to ignore. But research has been relatively scanty on its usage for knowledge sharing in bureaucratic organisations, where structural and procedural bottlenecks to knowledge sharing exist and where existing structures no longer fit the changing nature of the knowledge society. Some of the works reviewed were purely conceptual in nature, though it is a necessary foundation for a more rigorous empirical work. Also, there seems to be an agreement that social media impacts knowledge sharing practices in some ways. However, it is apropos to state that not all social media applications or tools have similar acceptability, capability, and level of effectiveness, when it comes to knowledge sharing. It is necessary to reduce this blur by paying attention to specific social media tool.

\section{RESEARCH METHODS}

This paper adopted the qualitative method of semi-structured interview for gathering research data. The method was chosen to facilitate the collection of rich descriptive data and enable the researchers to probe deeply and gather requisite information to achieve a holistic understanding of the subject matter. Furthermore, its flexibility gave room for follow-up questions to elicit more information on issues raised during the interview process.

The purposive sampling technique was adopted with the intent of selecting information-rich respondents to gain insights about pertinent issues central to the topic of interest. Since this study was delimited to the utilisation of Facebook for knowledge sharing with the external constituents (public) of the organisations, we purposively selected employees that were (1) highly knowledgeable and conversant with its activities in this regard, and (2) able to furnish the study with credible and optimal information on the area of focus. The selected employees were drawn extensively from the management cadre (top-level management) and the information units of the councils. A total of thirty-six respondents were interviewed, twenty from Oshimili South and sixteen Oshimili North local government council. It is pertinent to state that the selection of the local government councils was anchored on having an existing or active Facebook account. Out of twenty-five local government councils in Delta State, two had an existing Facebook account and were selected.

The interview guide was pre-tested using the cognitive testing to ensure the intended questions elicit consistent and complete information during the interview. Five respondents were randomly selected from each of the two groups to identify whether there may be interpretation errors or question design problems. Following the responses, the researchers discussed with the respondents as to why they answered in the way they did, and their thought about the answers (responses) and questions. 
The interview guide was deemed comprehensible enough for respondents to provide information in tandem with the topic of interest (see Appendix).

The interviews were done in person and onsite individually, typically running for ten minutes. The process was tape recorded to avoid chances of misquotes and misrepresentation of facts. Before each interview, the researchers provided the information sheet, stating the name, institutions involved, aims of the study, nature of the questions to be asked and length of the interview. Each respondent was given the opportunity to ask questions before, during, and after the interview. The indepth interviews were transcribed verbatim. The respondents were given ample opportunity to review the transcripts in a critical manner, as a precaution against possible misunderstandings and errors.

Thematic content analysis of interview transcripts was conducted to yield findings. The analysis of the transcripts began after the interview. Each transcript was read at least twice, during which core concepts were identified and aptly examined for similarities and differences. Codes were assigned manually to establish meaningful patterns from the identified concepts, and these codes were further developed into themes. The import of this was to reduce incidence of variation in the data analysed. This invariably makes it more précised. The codes assigned were pre-determined from the stated research objectives, but to allow for better flexibility the study gave room to accommodate emergent concepts that could have significant bearing on the research findings. After the initial pawning of the data, the researchers independently identified and arranged similar quotes into categories through cutting and sorting, with the intent of generating a long list of possible themes when both data are compared.

\section{FINDINGS \& DISCUSSION}

This section presents research findings from the thematic content analysis of interview transcripts which reduced the collected materials to an apprehensible and explicable form. The content is organised into two subsections by the following a priori themes: the impact of Facebook use on inward knowledge sharing and on outward knowledge sharing.

\section{IMPACT ON INWARD KNOWLEDGE SHARING}

The respondents are of the view that the use of Facebook has not been really significant for receiving or seeking pertinent information within agencies and from their stakeholders. The councils have not embraced the opportunity to engage, interact with, and listen to the stakeholders with regards to comments, opinions, or suggestions through Facebook. The bureaucratic nature of the councils apparently limits the manner in which they automatically listen to contributions or feedback unless it comes through formalised communication channels. However, they do believe that some information may be useful to their operation, but are constrained from verifying and reacting because of the policies that stipulate the way they receive such information. Even if the information is considered reliable and having immense value, they still are required to follow the due process with a formal notification, normally in writing, before the councils can act. The intermittent access to Facebook has been a factor limiting effective inward knowledge sharing, because knowledge has a tendency to change its form or lose its meaning when it is not accessed and utilised at an appropriate time. Generally, the councils do not have a dedicated smart device or computer for constant access to its Facebook page. The personal device of any employee in the information unit is used only when an information item is to be posted on the page. Although the conventional communication channels are lengthy and tiring and the councils are most of the time slow to respond and act accordingly, there is a glaring preference for the conventional communication channels (mass media and correspondence) in seeking first-hand information. This is because many individuals and the councils have not yet fully come to terms with Facebook as a forum for interacting with stakeholders and seeking their feedback. The respondents highlighted that this is another possible use of Facebook the councils would 
like to exploit, if the right structure and resources are put in place to effectively manage possible knowledge inflows.

\section{IMPACT ON OUTWARD KNOWLEDGE SHARING}

The respondents agree that the use of Facebook had little impact on the sharing of knowledge with the public, for the reason that they have not fully exploited its potential in this regard. The information shared on Facebook captures the activities of public servants in the executive section of the councils. The civil servants and members of the legislative section were well aware of their respective council's Facebook page, but barely made use of it to inform, update, and educate the public on their activities. However, Facebook use in the councils is lopsided because the information captured communicates the programs, projects, and official engagements of public servants in the executive section. The bureaucracy inherent in these organisations placed a major constraint on the type of information shared and discussed on Facebook, with preference still given to the traditional communication channels to inform, interact, and discuss real societal issues. This is because (a) many individuals were not tech savvy or compliant, (b) there was limited access to the internet and smart devices, and (c) there were no established clear guidelines for the use of Facebook for sharing actionable information. The respondents recognised that Facebook does serve a purpose in their knowledge management paradigm, but it will take time to fully appreciate the technology as a veritable tool for sharing information with the public.

In nutshell, it is apparent that Facebook has not been used for sharing actionable or meaningful information with the public, but the respondents did note some progress in this regard. The information shared was strictly for creating awareness, more like press releases, and it may not necessarily be actionable. This finding is contradictory to the observation made by some authors (Dunu \& Uzochukwu, 2015; Flanagin \& Bator, 2011; Mickoleit, 2014; Mosha et al., 2015; Vacquez \& Velez, 2011) that social media enables organisations to engage and listen to the meaningful suggestions and contributions (feedback) of corporate partners or stakeholders in the governance process in order to discover and improve service problems that can cause gaps between the organisation's targets and achievements. On the other hand, it is in agreement with McCorkindale's (2010, as cited in AndohQuainoo \& Annor-Antwi, 2015) finding that communication on the Facebook page in many public organisations is one-sided, resembling a monologue, and that its potential of two-way communication is yet to materialise. Despite the countless potential that social media brings to synchronous communication, many public organisations seem to view social media primarily as a one-way channel of sharing information. To some extent, the finding supports Aizhan et al.'s (2017) view that public organisations in a bid to keep stakeholders informed on their activities post operational or servicerelated information for public consumption on Facebook. It remains to be determined if comments and suggestions posted on social media directly influence operational or service-related policies.

\section{CONCLUSION}

This study investigated the utilisation of Facebook for knowledge sharing in selected local government councils in Delta State, Nigeria. By interviewing staff members who had access to Facebook accounts operated by their respective local government councils, the study found that the local government councils were yet to appreciate and utilise the interactive and collaborative features of Facebook in improving stakeholders' engagement, feedback, and cooperation. Facebook was used for outward knowledge sharing, but not for inward knowledge sharing.

In theory, the use of social media (with Facebook in particular) in public sectors may represent a fundamental shift in knowledge management. It can serve as an additional communication channel for the inputs of stakeholders and innovative ideas to be turned into new public services that are reliable and efficient. It increases transparency in dealings and interactions, which breeds trust and confidence. However, the study found that this has not been the case in local government councils in Delta State, Nigeria, possibly due to the bureaucratic nature of the councils, their strong dependence 
on conventional communication channels, relatively low proficiency in the use of technology, and limited access to the internet and web-enabled devices.

The study concluded that for knowledge sharing to be robust, effective, and efficient, local government councils have to change their knowledge sharing practices from the broadcast communication mode as presently seen to an interactive, two-way communication mode by effectively taking advantages of social media technologies such as Facebook for social engagement, interaction, and collaboration, whilst ensuring a good fit with policies, organisational structure, and resource allocation. The study recommends that local government councils encourage interaction via Facebook, show willingness to capture knowledge from identifiable sources, and effectively manage critical knowledge assets in order to build trust, cooperation, and confidence in the system. To gain strategic benefits from the use of Facebook for synchronous communication of knowledge, local government councils should ensure that the use of such technology is aligned with strategic planning and that directional change is in line with the new knowledge economy, where interaction and collaboration through technology are seen as strategic imperatives for continued success and sustainability. In addition, local government councils need to train stakeholders on effective use of Facebook for knowledge sharing, with special emphasis on how, why, who, when, and where to use such tool for knowledge sharing activities.

The findings summarised above need to be taken with consideration of some limitations of this study. The population was too narrow and the study relied extensively on the subjective insights of respondents purposively selected. To an extent, this could limit the generalisation and applicability of findings. In addition, the study focus was entirely on local councils in a particular state (Delta) in Nigeria. Future studies should pay close attention to research with a larger sample size and/or geographic region; and consider a comparative study based on ownership structure - federal, state, and local to broaden our understanding and fill in knowledge gaps.

\section{REFERENCES}

Andoh-Quainoo, L., \& Annor-Antwi, P. (2015). The use of social media in public relations: A case of Facebook in the Ghanaian financial services industry. New Media and Mass Communication, 41(1), 37-47.

Aizhan, T., Massimo, F., \& Cluadia, P. (2017). Use of social media for e-government in the public health sector: A systematic review of published studies. Government Information Quarterly, 34(2), 1-13. Retrieved 25 July, 2017, from www.sciencedirect.com

Awodoyin, A., Osisanwo, T., Adetoro, N., \& Adeyemo, I. (2016). Knowledge sharing behaviour pattern analysis of academic librarians in Nigeria. Journal of Balkan Libraries Union, 4(1), 12-19.

Bamgboje-Ayodele, A. \& Ellis, L. (2015). Knowledge management and the Nigerian culture: A round peg in a square hole. The African Journal of Information systems, 7(1), 1-20.

Baporikar, N. (2014). Knowledge management initiatives in Indian public sector. In A. Yousif, Building a competitive public sector with knowledge management strategy (pp 53-89), Hersey PA, IGI Global.

Chan-Olmsted, M. S., Cho, M., \& Lee, S. (2013). User perceptions of social media: A comparative study of perceived characteristics and user profiles by social media. Online Journal of Communication and Media Technologies, 3(4), 149-178.

Chinedu, O., Chinonye, F., \& Obi, I. (2016). Social media as a political platform in Nigeria: A focus on electorates in South-Eastern Nigeria. IOSR Journal of Humanities and Social Science, 21(11), 6-22.

Chow, C. W., Ho, J. L., \& Vera-Muñoz, C. S. (2008). Exploring the extent and determinants of knowledge sharing in audit engagements. Asia-Pacific Journal of Accounting and Economics, 15(2), 141-160.

Cross, R., Parker, A., Prusak, L., \& Borgatti, P. S. (2001). Knowing what we know: Supporting knowledge creation and sharing in social networks, Organizational Dynamics, 30(2), 100-120.

Danbatta, U. (2017, June 17). Role of social media in the social, economic and political development of Nigeria. The Premium Times. Retrieved from http://www.premiumtims.ng.com 
Utilisation of Facebook for Knowledge Sharing

Dunu, I. (2013). Good governance in Nigeria: What role for the media. European Scientific Journal, 9(32), 178197.

Dunu, I. V., \& Uzochukwu, C. E. (2015). Social media: An effective tool for social mobilisation in Nigeria. IOSR Journal of Humanities and Social Science, 20(4), 10-21.

Dzekashu, G. W. (2015). Tacit knowledge capture: A quality management imperative for attainment of operational excellence. Milton Keynes, Lightening Source UK Ltd.

Falco, T. (2011). Taking social media public: Social media for successful citizen relationship management. New York: IBM Global Services.

Federal Ministry of Agriculture and Rural Development. (2015). Knowledge management framework for stakeholders in the agricultural sector in Nigeria. Abuja, FMARD.

Flanagin, A., \& Bator, M. (2011). The utility of information and communication technologies in organizational knowledge management. In E. H. Canary \& D. R. Mcpee (Eds.), Communication and organisational knowledge: Contemporary issues for theory and practice, (pp. 173-190). NY: Routledge.

Gaál Z, Szabó L, Obermayer-Kovács N \& Csepregi A. (2015). Exploring the role of social media in knowledge sharing. The Electronic Journal of Knowledge Management, 13(3), 185-197.

Gibbs, J., Rozaidi, A. N., \& Eisenberg, J. (2013). Overcoming the ideology of openness: Probing the affordances of social media for organizational knowledge sharing. Journal of Computer-Mediated Communication, 19(1). 102-120.

Gregson, J., Brownlee, M. J., Playforth, R., \& Bimbe, N. (2015). The future of knowledge sharing in a digital age: Exploring impacts and policy implications for development. England: Institute of Development Studies.

Laihonen, H., \& Lonnqvist, A. (2011). How knowledge assets are transformed into value: The case of knowledge flows and service productivity. In S. Giovanni, Managing knowledge assets and business value creation in organizations: Measures and dynamics, (pp. 173-187). Hersey, PA: IGI Global.

McKinsey Global Institute. (2012). The social economy: Unlocking value and productivity through social technologies. Retrieved 10 November, 2016, from www.mckinsey.com

Mickoleit, A. (2014), Social media use by governments: A policy primer to discuss trends, identify policy opportunities and guide decision makers, OECD Working Papers on Public Governance, No. 26, Paris: OECD Publishing.

Mosha, F. N., Holmner, M., \& Penzhorn, C. (2015). Utilisation of social media tools to enhance knowledge sharing among knowledge workers: A case of Nelson Mandela African Institution of Science and Technology (NM-AIST), Arusha, Tanzania. Available from http://library.ifla.org/

Munro, L. (2014). The dynamics of business communication: A look at social media use in the workplace. Honors Theses. Paper 2491.

Muphy, G. D. (2010) Using Web 2.0 tools to facilitate knowledge transfer in complex organizational environments: ICOMS Asset Management Conference. Available at www.researchgate.net

Obermayer-Kovács, N., \& Wensley, A. (2012). Social media in organizations: Leveraging knowledge sharing. Pannon Management Review, 4(1), 25-65.

Okoro, N., \& Nwafor, K. A. (2013). Social media and political participation in Nigeria during the 2011 general elections: The lapses and the lessons. Global Journal of Arts, Humanities and Social Sciences, 1(3), 29-46.

Olajide, A. A., \& Oyeniran, K. G. (2014). Knowledge and use of social media among Nigerian librarians. Library Philosophy and Practice (e-journal). Paper 1145.

Olayiwola, V. O. (2014). Decoding the potency of Web 2.0 in Nigeria. International Journal of Politics and Good Governance. 5(5), 1-14.

Olufemi, J. F. (2012). Electronic governance: Myth or opportunity for Nigerian public administration? International Journal of Academic Research in Business and Social Sciences, 2(9), 122-140.

Omede, A. J. (2015). Social media: A trend or threat to democracy? Journal of Research in National Development, 13(1), 272-278. 
Serrat, O. (2010). Social media and the public sector. Available at www.adb.org

Teece, D., \& Pisano, G. (1994). The dynamic capabilities of firms: An introduction. Industrial and Corporate Change, 3(3), 537-556.

Vasquez, L. M. G., \& Velez, I. S. (2011). Social media as a strategic tool for corporate communication. Revista Internacional De Relaciones Públicas, 2(1), 157-174.

Wen, T. (2011). Achieving knowledge sharing outcomes through the activation of social capital in virtual communities: Evidence from Chinese online social network communities. Unpublished Doctoral Thesis. City University of Hong Kong, Hong Kong.

\section{APPENDIX}

\section{INTER VIEW GUIDE}

At the start of the interview process, there will be a verbal introduction of the interviewer and interviewee to establish a rapport and allow the interviewer to have background information of the interviewee. The purpose of the study, motivation behind the study, and time frame of $15 \mathrm{mins}$ for the interview process will be communicated in clear terms to the interviewee. The questions below sought to find out the degree of familiarity with the councils' Facebook activities, and to ascertain if Facebook usage influenced either or both inward and outward knowledge sharing. Follow up questions shall be asked to clarify issues raised or buttress more on the subject matter.

1. How conversant are you with the Facebook page of your organisation?

2. How is the followership on your Facebook page like?

3. How frequent do you share information on Facebook?

4. Can you ascertain the type of device used to share information on Facebook?

5. Can you please tell me the type of information shared or not shared on Facebook?

6. How well do you interact or respond to comments on Facebook?

7. Does your organisation listen to suggestions and comments on their Facebook wall?

8. Do you consider such information as actionable?

9. Can you give any instances where such suggestions or comments were taken into consideration, if any?

10. What are your views of Facebook as a veritable tool for sharing actionable information?

11. Do you consider Facebook as a proper platform or channel for public dialogue?

12. Generally, do you think Facebook has or has not affected the way your organisation interact and share information with the public? 


\section{BIOGRAPHIES}
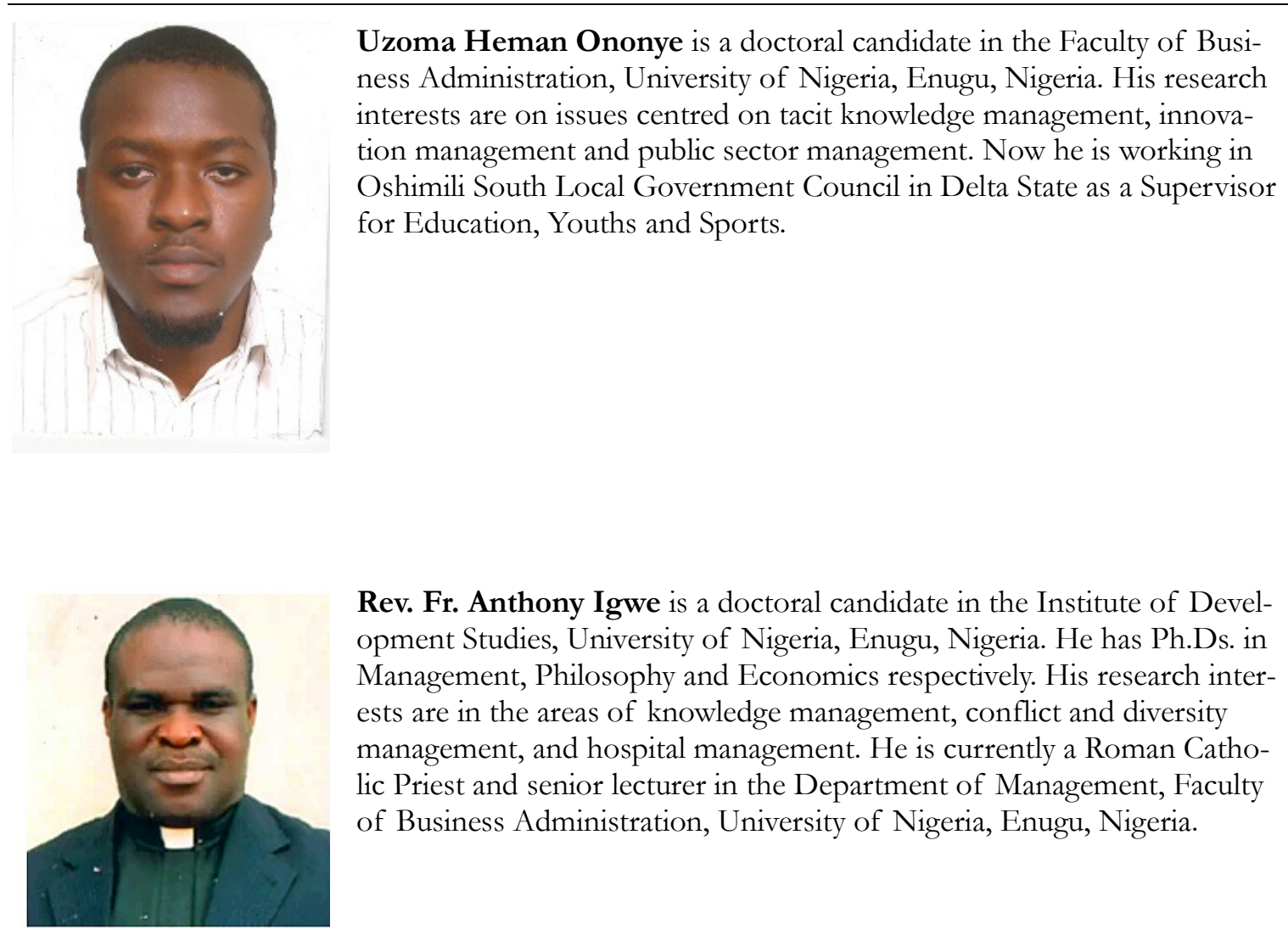

Rev. Fr. Anthony Igwe is a doctoral candidate in the Institute of Development Studies, University of Nigeria, Enugu, Nigeria. He has Ph.Ds. in Management, Philosophy and Economics respectively. His research interests are in the areas of knowledge management, conflict and diversity management, and hospital management. He is currently a Roman Catholic Priest and senior lecturer in the Department of Management, Faculty of Business Administration, University of Nigeria, Enugu, Nigeria. 